\title{
Perspectives for effective integration of e-learning tools in university mathematics instruction for developing countries
}

\author{
Edwin Akugizibwe ${ }^{1}$ (D) Jeong Yong Ahn ${ }^{2}$
}

Received: 21 May 2019 / Accepted: 9 August 2019 / Published online: 31 August 2019

(C) The Author(s) 2019

\begin{abstract}
This paper analyses student views on an e-learning intervention that incorporated a content development tool and computer algebra systems, aimed at improving performance and applicability of mathematics knowledge. The study deliberately relied on open source tools, with high usability both online and offline, that can be customized to address the peculiarities of mathematics instruction in developing countries. Repeated ANOVA and logistic regression were among the statistical methods used to analyze the data. Key findings showed that usability and detailed feedback were the qualities of computer algebra system that were most desired by students. Content quality, problem solving abilities and internet availability were key factors for mathematical e-learning satisfaction. The research showed that the use of an interactive content development tool and computer algebra systems can help the teachers to be more innovative and adopt project-based examination formats that encourage knowledge applicability. The e-learning tools helped the students to self-regulate and discover their own knowledge, which increased their chances of handling application type problems. Among others, the study recommended set up of mathematical e-laboratories which can be accessed by students for at least 3 days per week.
\end{abstract}

Keywords Assessment and feedback · Dynamic and interactive content · Content development tool $\cdot$ Computer algebra systems $\cdot$ Knowledge application $\cdot$ Logistic regression

Electronic supplementary material The online version of this article (https://doi.org/10.1007/s10639-01909995-z) contains supplementary material, which is available to authorized users.

Edwin Akugizibwe

akugizibweedwin77@gmail.com

1 Department of mathematics, Mountains of the Moon University, Fort Portal, Uganda

2 Department of Statistics (Institute of Applied Statistics), Chonbuk National University, Jeonju, South Korea 


\section{Introduction}

Like it is in the developed world, most universities in developing countries like Uganda incorporate mathematics content in many of the programs they teach to students. This reflects the vital role mathematics is expected to play in producing high quality, productive and innovative workforce in a country. However, the teaching and learning of university mathematics in countries like Uganda is still engulfed in a multitude of problems that include poor performance, low student morale, poor content delivery and absence of knowledge application (Namukasa et al. 2010). Among other interventions, many universities have attempted to introduce e-learning to improve the teaching and learning process. These early e-learning interventions have tended to be general but not subject specific and have focused mainly on interplay between distance and blended learning. Thus, for such countries, there is currently insufficient effort geared specifically towards effective implementation of university level mathematical e-learning.

This study intended to solicit students' perspectives on a mathematics e-learning intervention that incorporated the use of both a content development tool and computer algebra systems. The intervention intended; (i) to improve interest, motivation and performance and (ii) to improve creativity and knowledge applicability in learners. The intervention consciously relied on easy to install and use, open source technologies since cost/affordability, usability and impact of the e-learning technologies are paramount for developing countries like Uganda. Consequently, a post e-learning survey was conducted to answer the following research questions;

(i) What attributes do students like most in mathematical e-learning tools?

(ii) What are the key factors for successful mathematical e-learning?

(iii) What is the appropriate content and pedagogy approach to induce creativity and knowledge applicability among learners?

\section{Literature review}

E-learning tools used in mathematics instruction are generally of two types namely elearning platforms and computing tools. An e-learning platform is a content development tool (CDTs) or virtual learning environment (VLEs) through which it is possible to develop and deliver training courses; administer and monitor them; and access a series of facilities and arrangements (Slătineanug et al. 2015). A computing tool as used here is any electronic equipment or software that can input data, manipulate it mathematically and output it in numeric, symbolic or graphic form. This broad definition encompasses electronic calculators, computers algebra systems (CAS) and some statistical programs. A computer algebra system (CAS) is a software program that facilitates manipulation of mathematical formulae both symbolically and numerically.

From inception, mathematicians have relied on tools of various kinds to solve or elucidate mathematical problems. The early mathematicians used analogue tools such as slide rule until 1940s when digital computers were used for cryptography and later in the 1950s for numerical approximations in applied mathematics. Adoption of digital computing tools for usage in school or classroom environments was possible after the inception of portable electronic calculators in 1970 and the dawn of IBM's personal 
digital desktop computer in 1981 (Wright 2010). Currently, an array of CAS such as Matlab, Maple, Mathematica and statistics packages such as SPSS (commercial) and $R$ (open source and free) are widely available as, not just toys for learning, but also as professional research tools; mastering them is a valuable transferable skill for graduates seeking employment in mathematics-intensive industries (Borovik 2011).

Notwithstanding the many advantages of adopting mathematical e-learning, Buteau et al. (2014) in a Canadian survey, reported a lack of enthusiasm by teachers towards using CAS in mathematics classes. Similarly, Borovik (2011) quoted a 2010 teaching position statement from the London Mathematical Society that stated, "Not every area of study needed or was compatible with e-learning, and so to assume it would grant blanket advantages was not accurate". According to Buteau et al. (2014), the time required for developing CAS-related teaching material, and the tight class time making it difficult to add CAS-related activities, were the two most significant factors inhibiting teachers' utilisation of CAS. Teachers surveyed also warned that overreliance on CAS may hinder students from acquiring the underlying mathematical concepts. We observe that without a well-planned mathematical e-leaning intervention effort, time constraints and exam-oriented approach dominant in mathematics education across Africa and other developing countries could be a hindrance to adoption of CAS.

Relatedly, despite mathematicians being the first to use IT in teaching, the wide scale adoption of e-learning platforms is still drawing mixed feelings among mathematicians. The challenge according to Borovik (2011) is that there has been a discrepancy in terms of levels of development between CAS and e-learning platforms. While a high level of sophistication has already been achieved with CAS tools such as Matlab/Maple, many existing e-learning platforms currently available do not meet the functionality required by mathematicians. As an example, e-learning platforms are unusable in mathematics learning and teaching if they do not support math-text such as LaTeX. We note that currently most e-learning platforms can accommodate math-text. However, it is usually enabled on the editor or teacher's interface but not on the student's interface, making it difficult for students to give math-text enabled feedback.

It is clear therefore that it requires a right combination of e-learning platforms and/or CAS, as well as meticulous preparation of content by teachers to create a proper fully packaged mathematics e-learning experience. Indeed, success stories of using elearning platforms or CAS in mathematics instruction exist. Lui et al. (2013) designed a system which highlighted the use of virtual manipulative e-learning platforms for mathematics which can enable a high level of interactivity among students while they solve mathematical problems. For example, students can experiment with different input parameters and observe the effects on the outcome. Some online mathematics platforms such as Khanacademy (www.khanacademy.org) and MUMIE (www.mumie. net) provide good case studies of simple but effective math text supported and interactive e-learning platforms. They illustrate the importance of an e-learning platform enabling math-text on both teacher side and student side as well as enable learners to try a problem again and again while providing step by step hints and solutions. On the other hand, authors like Kramarski and Hirsch (2003) and Kendal et al. (2005) have reported on the success of using CAS in their mathematics lessons. Key to these interventions, the teachers still played a crucial role at some time during the lesson. The teachers stressed the need for students to have a good understanding of concepts and to be mindful of the different CAS properties. The teachers also observed that 
"when using CAS for assessment, calculation can no longer be used to assess understanding and knowledge of patterns. Instead, there is a need to create new strategies for highlighting reasoning, explanations and connections in mathematical work" (Kendal et al. 2005). Most of these studies have reported using either e-learning platforms or computing tools but not both. In the next section, we discuss our study, which focused on integrating both a content development tool and computing tools in classroom environment, aimed at improving performance and applicability of mathematics knowledge.

\section{Methodology}

The study involved all the 39 first-year mathematics major students of Mountains of the Moon University (MMU), Uganda undertaking a course of Linear Algebra 1. The study used a combination of a content development tool called Xerte online toolkits (XOT) (www.xerte.org.uk) and 2 computing tools namely; Matrix calculator (https://matrixcalc.org/en/det.html) and $R$ (https://cran.rproject. org/bin/windows/base/). These tools were chosen because they are open source, can easily be installed on computers, are user-friendly and can work online and offline. These properties are desirable for rural based universities in developing countries where many logistical challenges of low skills, low internet connectivity still exist.

The process of content formation involved using XOT's interactive icons such as button sequence, dialogue, drag and drop, gap fill to produce content that is highly motivating, interactive and with dynamic evaluation. For example, in Fig. 1, we show a practice exercise in $X O T$ with an interactive step by step solution. This provides both the lecturer and the students a chance to highlight the key steps of solving a problem.

The XOT content could then be given to students as a compressed file which they would simply unzip and run the index.htm to view it. Alternatively, XOT content could easily be uploaded as a SCORM package to other learning management systems like Moodle (Misselbrook 2008). A detail of the XOT work we prepared can be accessed on the MMU website (http://elearning.mmu.ac.ug/).

The classroom delivery of the content involved a blended approach in which the teacher explained the XOT content and demonstrated use of the XOT interactive icons. The $X O T$ content was then supplemented with the use of $R$ and Matrix calculator as computing tools. $R$ is a programming language mainly used for statistical analysis but can handle Linear Algebra related problems well and is increasingly being used for mathematical instruction (Bamberg, 2015). Matrix calculator is simple "plug and play tool" that gives detailed working of the problem in a step by step manner familiar to the students. The computing tools were used alternatively to enable students compare their attributes. The students were using the e-learning tools for the first time and had received one-week training prior to the experiment.

The study was conducted within 8-weeks period from September to October 2018. At the end of the study, a survey was given to students to obtain their views on the mathematics e-learning experiment. We present the survey results in the next section. 


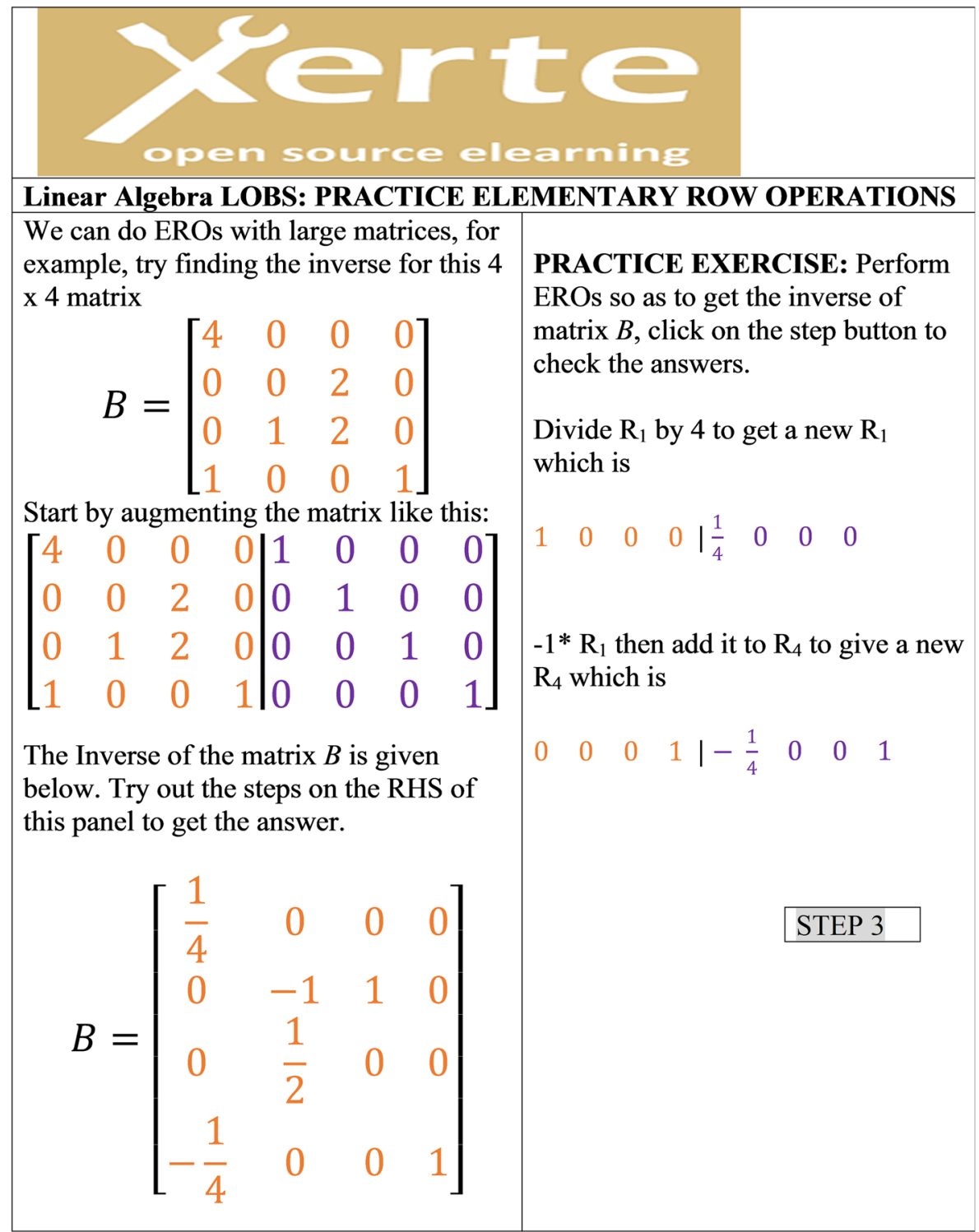

Fig. 1 Step by step button sequence interactivity in XOT

\section{Results}

\subsection{XOT assessment}

The students were required to rate various $X O T$ attributes using a 5-point Likert scale ranging from strongly disagree to strongly agree. The most liked features were content design (86.4\%), interest (81\%) as well as the XOT interactive features such as drag and place $(81.8 \%)$, drop down icon $(86.4 \%)$ and its ability to keep them engaged $(81.8 \%)$. These attributes enable students to study mathematics in a more captivating way while 
highlighting the key aspects of the content. Indeed, the students reported that the content was easier to understand $(77.3 \%)$, appealing (60\%), enjoyable $(63.6 \%)$ and interactive $(65.2 \%)$. However, 36.4\% disagreed with the assertion that the XOT tool by itself can help them understand better compared to traditional learning format. This reemphasizes the necessity of the teachers' presence, guidance and explanation for effective mathematics learning even with availability of e-learning. This result supports the general approach of blended learning advocated by several scholars (Lin et al. 2017; Kintu et al. 2017).

\subsection{Comparing the various e-learning tools to the traditional approach}

In Table 1, students were asked to use a scale of 1 to 5 (1 as the lowest mark and 5 as the highest mark), to rate each of the e-learning tools used in comparison to the traditional method. We run repeated ANOVA tests on various attributes of the elearning tools as assessed by the students. In each case, the attribute rating was the dependent variable while e-learning type (Traditional, XOT, Matrix calculator $(M C), R$ ) was the independent variable. We present average student ratings for each attribute. The attributes were all subjected to Levene's test which showed that the assumption of homogeneity of variance was established. The normality test was done by histograms and normality plots. The normality test was not exactly fulfilled but we deemed the plots good enough to proceed with the repeated ANOVA test.

Generally, there was a statistically significant increase in rating for e-learning tools being user-friendly, engaging, interactive and improving knowledge applicability (all have $\mathrm{p}$ value $<0.05$ ). Clearly, the students found Matrix Calculator most user-friendly compared to other tools and this influenced their responses to other questions regarding the usage of the e-learning tools. The students showed a strong desire to study with all the 3 e-learning tools in future.

Table 1 Students assessment of the qualities of the e-learning tools

\begin{tabular}{llllll}
\hline Question & Traditional & $X O T$ & $M C$ & $\mathrm{R}$ & $P$ value \\
\hline The tool was user friendly & 2.33 & 2.85 & 4.7 & 3.0 & $0.000^{* * *}$ \\
The tool is engaging and captures student's attention & 3.08 & 3.38 & 4.5 & 3.5 & $0.0198^{*}$ \\
Gained better understanding of the content with tool & 2.77 & 3.62 & 3.86 & 3.00 & 0.114 \\
The tool enhanced applicability of the knowledge & 2.54 & 3.15 & 3.5 & 2.38 & $0.0436^{*}$ \\
Able to manipulate numbers and observe effect & 2.43 & 3.00 & 4.00 & 3.08 & $0.0479^{*}$ \\
The tool enabled me to re-attempt numbers I failed & 2.77 & 3.14 & 3.93 & 3.00 & 0.187 \\
The tool showed detailed explanation & 3.15 & 4.08 & 4.25 & 2.50 & 0.00121 \\
The tool's interactive icons improve understanding & 1.77 & 3.00 & 3.62 & 2.92 & $0.0043 * *$ \\
Enables simulations and stimulate understanding & 3.14 & 3.54 & 4.08 & 3.46 & 0.136 \\
I wish to study with this tool in the future & 1.85 & 3.00 & 4.86 & 3,08 & $0.000^{* * *}$ \\
I finished the tasks faster when using this tool & 1.62 & 3.00 & 4.64 & 3.54 & $0.000^{* * *}$ \\
\hline
\end{tabular}

$*$, **, *** statistically significant result at the $5 \%, 1 \%$ and $0.1 \%$ level of significance, respectively 


\subsection{Comparing students' interest and abilities in mathematics before and after e-learning}

In Table 2, we present the mean (standard deviation) of paired t tests we ran on various attributes to ascertain students' perspectives before and after the elearning intervention. The attributes were selected partly based on the work done by Willacy and Calder (2017).

We see that students' likeability of mathematics, ability to try out new problems in mathematics on their own, interest in using e-learning tools in mathematics, increased understanding and increased ability to solve problems had the highest rating among students and were statistically significant (all have $\mathrm{p}$ value $<0.05$ ). We employed factor analysis (see Table 5 of Appendix 2) to get any underlying concise interpretation of the attributes. This resulted in two key factors as showed next.

\section{Factor 1: Problem solving.}

Ability to understand mathematics topics studied

Ability to solve problems in the topics studied

Ability to learn at my own pace

\section{Factor 2: Knowledge applicability}

\section{I like mathematics generally}

I like using mathematics apps in my study

Ability to apply knowledge studied

Table 2 Students assessment before and after e-learning

\begin{tabular}{llll}
\hline Attribute & Before & After & p value \\
\hline How much do you like maths? & $3.80(0.94)$ & $4.50(0.73)$ & $0.027^{*}$ \\
How much do you like doing maths on your own? & $3.94(0.85)$ & $4.13(1.06)$ & 0.470 \\
How do you feel about doing things in maths you have not tried before? & $2.67(0.62)$ & $4.00(0.89)$ & $0.000^{* *}$ \\
The content related to my background knowledge and experience & $3.40(0.91)$ & $3.80(1.28)$ & 0.390 \\
How do you feel about using apps as part of your maths program? & $2.75(1.13)$ & $4.13(1.19)$ & $0.000^{* *}$ \\
How do you rate your understanding ability in the topics studied & $3.26(0.88)$ & $4.25(0.86)$ & $0.010^{*}$ \\
How do you rate your ability to apply the knowledge studied & $3.06(1.06)$ & $4.00(1.25)$ & $0.047^{*}$ \\
How do you rate your motivation to study mathematics & $3.50(1.06)$ & $3.87(1.20)$ & 0.530 \\
Capability to solve problems in the topics studied & $3.31(1.08)$ & $4.13(1.13)$ & $0.020^{*}$ \\
Capability of working together with others in a group & $3.93(0.88)$ & $3.88(1.09)$ & 0.690 \\
Capability to learn at your own pace & $3.00(1.21)$ & $4.13(1.13)$ & $0.010^{*}$ \\
The information presented in the e-learning & $3.00(0.93)$ & $3.31(1.62)$ & 0.640
\end{tabular}

*, ** statistically significant result at the $5 \%, 1 \%$ level of significance, respectively 
We see that the first factor which we identify as problem solving is associated with ability to understand the topics studied and ability for students to learn on their own pace or self-regulate. Thus, we conclude that according to students' own assessment, ability to understand the topics studied and ability to learn at their own pace were the biggest effects of the e-learning intervention which contributed to their ability to solve the mathematics problems. Similarly, we identify the second factor as knowledge application, and it is strongly associated with likeability of mathematics and likability of utilizing the mathematics e-learning tools. Thus, we conclude that for e-learning to have a significant effect on students' ability to apply mathematics knowledge, it should significantly increase their ability to like mathematics and the learners must have an ability to like or utilize the mathematics e-learning tools.

In summary, for the first research question, our study showed that interactive features of the e-tools, user-friendliness and ability to give step by step dynamic and detailed feedback were the attributes students desired most in elearning tools. These resulted in students' ability to solve problems at their own pace and apply the knowledge acquired. Our results are like those of Mohapatra and Patra (2017) who found out that "perceived ease of use, perceived usefulness/utility, attitude towards using a system or application and the design and implementation process" are vital for successful integration of technology in the learning process.

\subsection{Logistic regression model for factors influencing e-learning satisfaction}

Concerning the survey question that asked students to "rate your own satisfaction with the e-learning experience", the results showed that $63.2 \%$ of the respondents were satisfied while the rest were either undecided or not satisfied. Clearly, majority of the students rated the e-learning intervention well, yet a considerable other percentage of the students felt unsatisfied. We adopted a logistic regression model to determine the main factors that influenced the students' decisions. Many articles (e.g. POP 2012; Lengyel et al. 2017; Trehan and Joshi 2018) have used logistic regression in evaluating e-learning studies and the areas of interest are diverse, encompassing evaluation of classroom/online platforms, comparing two different platforms and general criteria for e-learning success.

For our model, the response variable is e-learning success. Both the response variable and all the categorical predictor variables were converted from a 5-point Likert scale to a dichotomous scale in which ratings of 4 or 5 were classified as good, high or agree while 1, 2 and 3 were classified as low, bad or disagree. We first tested the response variable (e-learning success) against each possible predictor variable in a univariate logistic model, keeping only those variables that return a $p$ value of less than 0.25 (Agresti, 2013). This approach gave us 13 possible predictor variables. We next tried various combinations of predictor variables from the possible 13 variables. We settled onto the final model below based on drop one criterion, backward selection, Akaike information criteria (AIC) and meaningfulness of the model

$$
\log \left(\frac{\text { Satisfied }}{\text { Not satsfied }}\right)=\beta_{0}+\beta_{1} \text { Skills }+\beta_{2} \text { Internet }+\beta_{3} \text { Content }+\beta_{4} \text { Problem solving }
$$


Skills, Internet and Content are dichotomous variables with base category being high and the other category being low. Problem solving is a continuous variable ranging from 1 to 5. Internet, Content and Problem solving were statistically significant (all have $\mathrm{p}$ value $<0.05)$. We give an explanation on each as below:

\subsubsection{Internet adequacy}

From Table 3, an assessment of internet adequacy as low compared to high changes the $\log$ odds of being satisfied with e-learning intervention by -2.946 . This means improved internet services would increase the chances of students' satisfaction with the elearning intervention. Improved internet access is certainly an issue that most universities in developing countries are working on. However, Internet adequacy here is also related to the number of days students have access to the university computers (see Table 4 of Appendix 1). This is so because majority of students in this survey reported a lack of personal computers. There is therefore a need to create a well-equipped mathematics laboratory with good internet which can be accessed by students at least 3 days a week.

\subsubsection{Content quality}

From Table 3, an assessment of content quality as low compared to high changes the log odds of being satisfied with e-learning intervention by -4.01 . This means improved content quality would increase the chances of students' satisfaction with the e-learning intervention. We observe that the variable measuring content quality was an aggregate of content related questions of XOT and they are; content was well designed; content was easy to understand; content was interesting. From this result, we therefore deduce that effective use of content development tools can substantially increase odds of mathematical e-learning satisfaction. It will necessitate teachers to periodically update their skills and abilities as well as to be committed to producing high quality work for e-learning to be fully successful and appreciated by the learners. Content quality was directly or indirectly identified by several other studies (POP 2012; Hassanzadeh et al. 2012; Lengyel et al. 2017).

Table 3 Factors influencing satisfaction rating of e-learning intervention

\begin{tabular}{lllll}
\hline Source & $\mathrm{B}$ & SE B & $\mathrm{Z}$ value & $\mathrm{p}$ \\
\hline Intercept & -3.417 & 3.411 & -1.002 & 0.316 \\
Skills & -2.548 & 1.323 & -1.926 & 0.054 \\
Internet & -2.946 & 1.542 & -2.026 & $0.043^{*}$ \\
Content & -4.01 & -1.50 & -2.77 & $0.006^{* *}$ \\
Problem solving & 7.351 & 3.63 & 2.02 & $0.043^{*}$ \\
\hline
\end{tabular}

*, ** statistically significant result at the $5 \%, 1 \%$ level of significance, respectively 


\subsubsection{Problem solving}

From Table 3, for every one-unit increase in problem solving abilities, the log odds of being satisfied with e-learning intervention increase by 7.351 . Problem solving as a factor is a measure of the confidence gained by the learners to tackle mathematics problems at their own pace and self-regulation due to the aid of the e-learning tools (see Table 5 of Appendix 2). This demonstrates that students will appreciate e-learning intervention in mathematics as successful if they perceive it to be having a positive impact in their ability to tackle the various mathematics challenges they encounter.

In summary, internet adequacy, content quality and improved problem-solving skills were perceived as most important for mathematical e-learning satisfaction among learners.

\subsection{Appropriate content and pedagogy approach for creative thinking and knowledge application}

A combination of using an e-learning platform and CAS gives a teacher great flexibility in how to arrange and deliver the content. But it requires the teacher to put in more preparation time and to think well about the process of evaluating students. Mohapatra and Acharya (2011) noted that for computer assisted learning (CAL) to be effective, the quality of teachers and mode of classroom delivery is important too. In this study, the general procedure was to start off by exposing students to real-life applications of the content to get them motivated to study the content. We would then use XOT to explain the content in an interactive manner. Then, we would later use the CAS to concretize the ideas. This combination of e-tools boosts active learning and helps the teacher explain salient concepts that would hitherto be difficult without the e-learning tools. In addition, the teacher can easily switch from traditional exam formats to application type format as illustrated in Fig. 2.

Here, the students were required to discover their own knowledge and solve an example of a real-life application problem. The availability of e-learning tools means that the students could concentrate more on interpretation and formulation of the problem. In solving the problem in Figs. 2, 28 students chose to use Matrix calculator, 4 chose $R$ while 2 chose to work manually. We provide the reasons the students gave to back up their choices;

Matrix Calculator

- It makes calculations easy thus making message decoding easy"

- It was easy to apply

- Because it shows the basic steps to reach on the final answer

- It is simple because answers are direct

Nevertheless, the two students who selected $R$ gave the reasons below;

- Bring the answer easily when used

- $R$ can show you where you have made a mistake and edit it then you will be able to notify it to get the required solution. 


\section{$\longrightarrow$}

(2)

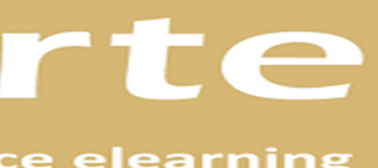

open source elezrning

\section{Application type format}

For this problem, you can work alone or in a group not exceeding four people. You can choose any of the methods you have used (Manual calculation, Matrix calculator, R) during the experiment. Submit your answer (hard or soft copy) and answer the research questions below;

\section{APPLICATION PROBLEM}

Study the application of linear algebra to Cryptography on the website below

\section{http://aix1.uottawa.ca/ jkhoury/cryptography.htm}

\section{QUESTION: Encode and decode the Message "I LOVE MOUNTAINS OF THE MOON UNIVERSITY”}

Fig. 2 Application type problem

The emphasis here was on ease of use and nature of output or feedback. Thus, overall, we see that usability and nature of feedback were the two main reasons for learners in choosing the two computing tools. More importantly, these tools helped the students to work on their own pace and solve this kind of application problems. Ability for students to self-regulate with the help of mathematical e-learning tools, is vital since past researches have showed that most students lack the motivation or self-drive to acquire mathematics knowledge beyond that of the classroom (Namukasa et al. 2010). Thus, we need a rightful mixture of blended learning, use of both content development tool and CAS to generate and deliver content that is appropriate to stimulate creative thinking and knowledge application among learners. Nonetheless, the teacher's role in preparing well to achieve the rightful pedagogy approach with mathematical e-learning is very important. Sarkar et al. (2018), in their study of a digital equalizer program that emphasized problem-based learning in India, stated that the teacher must always be at the heart of the system. They added that "we have always believed that the quality of a system can never exceed the quality of its teachers". 


\section{Conclusion and recommendations}

Most e-learning interventions that have sprung up in developing countries have been multipurpose and mainly aimed at online or distance learning or simply appealing to "modernising education process". However, these e-learning interventions have not been massively used by teachers or students. In other cases, they mainly serve as content delivery platforms, but with high maintenance costs (Mayoka and Kyeyune 2012). Our study clearly demonstrates that non-bulky, open source e-learning tools can be customised to handle specific subjects like mathematics. The various results and experiences while conducting this study led to the recommendations below:

Mathematics instruction for both synchronous and asynchronous learning should adopt e-learning to improve performance and applicability of knowledge. There are many available open source e-learning tools which make it highly feasible to adopt technology into mathematics instruction. Training courses on use of mathematics e-learning tools should be given to fresh students and teachers. There should be increased cooperation among teachers across various universities through conferencing. Students must have access to mathematics e-laboratories for at least 3 days per week.

An effective e-learning intervention requires use of content authoring tool first to explain basic concepts and later using computer algebra systems to concretize the concepts. In this way, mathematical e-learning will help to impart to learners those mathematical concepts that are rather difficult to explain under traditional learning. In this regard, the best approach should be an appropriate mixture of blended learning in which the teacher plays a key role but has the back up of mathematical e-leaning tools.

The mathematics content authoring tool should be simple and not too crowded on the student side. There should be mechanisms that allow note taking with math text support on both the teacher and student side of the platform. The platforms should enable learners to give feedback to the video, practice quiz and hints. Video technology involving both teachers and students explaining mathematics concepts should be the first option as medium of instruction for outside classroom environments like distance learning. In addition, the platform should encourage forums and community groups to share knowledge and experiences.

As adoption of e-learning tools in mathematics instruction increases, we realize that most of the problems that were done in classroom can now easily be performed by CAS. The role of mathematics instruction ought to change to embrace this realty. Teachers are called upon to be more innovative and adopt project-based examination formats that encourage knowledge applicability. This, after all, will prepare the students better for real life work situations compared to traditional examination formats.

\section{Further research recommendation}

This study was conducted within one semester. There is a need to have follow-up activities that span at least two semesters to learn how students' behavior towards mathematical e-learning changes over a longer period. Also, this form of e-learning intervention can be extended to other universities within Uganda and beyond. 


\section{Appendix 1: Relationship between Internet adequacy and computer access}

To explore the issue of internet adequacy more, we run a chi-square analysis relating internet adequacy to number of days the students reported as having access to a university computer in a week. Access to a computer for 3 or more days was deemed good while less than 3 days' access was deemed bad. The chi square results are reported in Table 4.

Table 4 Results of Chi-square Test and Descriptive Statistics for Internet adequacy by computer access

\begin{tabular}{llr}
\hline Access & Internet adequacy & \\
\cline { 2 - 3 } Adequacy & High & Low \\
\hline Good & $12(20 \%)$ & $3(5.1 \%)$ \\
Bad & $8(13.6 \%)$ & $36(61 \%)$ \\
\hline
\end{tabular}

$\chi^{2}=19.08, \mathrm{df}=1$. Numbers in parentheses indicate total percentages. $* * * p<.0001$

For the chi-square test, our null $\left(\mathrm{H}_{0}\right)$ and alterative $\left(\mathrm{H}_{1}\right)$ hypotheses are as below.

$\mathrm{H}_{0}$ : Internet adequacy and computer access are not related.

$\mathrm{H}_{1}$ : Internet adequacy and computer access are related.

We have a high chi-squared value and a $p$ value of less than 0.05 significance level. So, we reject the null hypothesis and conclude that internet adequacy and computer access are related. This then shows that internet adequacy is not directly an issue to do with the performance of the e-learning tools but rather is related to the opportunities availed to students to practice with the e-tools. This calls for a concerted effort to enable students increased access to e-learning tools within university premises. One sure way will be to create special mathematics e-laboratories which students can access for at least 3 days per week.

\section{Appendix 2: Factor Analysis of Table 2 attributes}

We employed factor analysis to get any underlying concise interpretation of Table 2 attributes. For each attribute, we used a new variable formed as the ratio of the students' rating of each attribute after and before e-learning (After/Before) and we present the results in Table 5 .

The three factors contribute almost equally to explaining the sample variance and the cumulative variance of the three factors is 0.79 , which is a sufficient proportion. To interpret the factors, we selected attributes of factor loadings above 0.7 (bold in Table 5) but only included the attributes that were significant (from Table 2). This resulted in dropping the third factor and remaining with Factor 1and Factor 2 which were explained in the section of results 
Table 5 Factor loadings and communalities based on principle components analysis with Varimax rotation for 12 items comparing student abilities before and after e-learning

Loadings

Attributes

F1

F2

F3

I like mathematics generally

$\begin{array}{lll} & \mathbf{0 . 8 2} & 0.52 \\ \mathbf{0 . 8 1} & -0.35 & -0.24 \\ -0.24 & 0.43 & \\ & \mathbf{0 . 7 5} & \\ 0.15 & \mathbf{0 . 8 1} & 0.39 \\ \mathbf{0 . 8 4} & & 0.40 \\ 0.18 & \mathbf{0 . 8 7} & 0.40 \\ \mathbf{0 . 7 4} & 0.51 & -0.26 \\ \mathbf{0 . 8 4} & 0.19 & -0.20 \\ 0.36 & -0.24 & -0.73 \\ \mathbf{0 . 8 1} & & -0.56 \\ -0.12 & 0.15 & \mathbf{0 . 9 4} \\ 0.29 & 0.57 & 0.79\end{array}$

Factor loadings $<.2$ are suppressed, extraction method is principal component analysis and rotation method is varimax

Open Access This article is distributed under the terms of the Creative Commons Attribution 4.0 International License (http://creativecommons.org/licenses/by/4.0/), which permits unrestricted use, distribution, and reproduction in any medium, provided you give appropriate credit to the original author(s) and the source, provide a link to the Creative Commons license, and indicate if changes were made.

\section{References}

Agresti, A. (2013). Categorical Data Analysis, 3rd edition. Hoboken, NJ: John Wiley \& Sons

Bamberg, P. G. (2015). Adventures of using R to teach mathematics. Boston: Havard Univeristy. Retrieved from https://www.slideshare.net/odsc/paulbambergadventurespresentation. Visited on 2019/05/23rd

Borovik, A. (2011). Information technology in university-level mathematics teaching and learning: A mathematician's point of view. Research in Learning Technology, 19(1), 73-85. https://doi.org/10.1080 /09687769.2010.548504.

Buteau, C., Jarvis, D. H., \& Lavicza, Z. (2014). On the integration of computer algebra systems (CAS) by Canadian mathematicians: Results of a National Survey. Canadian Journal of Science, Mathematics and Technology Education, 14(1), 35-57. https://doi.org/10.1080/14926156.2014.874614.

Hassanzadeh, A., Kanaani, F., \& Elahi, S. (2012). A model for measuring e-learning systems success in universities. Expert Systems with Applications, 39(2012), 10959-10966.

Kendal, M., Stacey, K., \& Pierce, R. (2005). The influence of a computer algebra environment on teachers' practice. In D. Guin, K. Ruthven, \& L. Trouche (Eds.), The Didactical Challenge of Symbolic Calculators. Mathematics Education Library (Vol. 36). Boston: Springer. https://doi.org/10.1007/0-38723435-7 5.

Kintu, M. J., Zhu, C., \& Kagambe, E. (2017). Blended learning effectiveness: The relationship between student characteristics, design features and outcomes. International Journal of Educational Technology in Higher Education, 14(7). https://doi.org/10.1186/s41239-017-0043-4. 
Kramarski, B., \& Hirsch, C. (2003). (2003). Using computer algebra systems in mathematical classrooms. Journal of Computer Assisted Learning, 19, 35-45. https://doi.org/10.1046/j.02664909.2003.00004.x.

Lengyel, P., Herdon, M., Pancsira, J., Ráthonyi, G., \& Füzesi, I. (2017). The effectiveness of the E-learning applications: Assessment of the service quality using binominal logistic regression. Journal on Efficiency and Responsibility in Education and Science, 10(2), 51-57, online ISSN 1803-1617, printed ISSN 23362375. https://doi.org/10.7160/eriesj.2017.100203.

Lin, Y. W., Chih-Lung Tseng, C. L., \& Po-Jui Chiang, P. J. (2017). The effect of blended learning in mathematics course. EURASIA Journal of Mathematics, Science and Technology Education, 13(3), 741-770.

Lui, R. W. C., Lo, K. K. Y., \& Yiu, S. M. (2013). Evaluating and adopting e-learning platforms. International Journal of e-Education, e-Business, e-Management and e-Learning, 3, 3. https://doi.org/10.7763 /IJEEEE.2013.V3.229.

Mayoka, K. G., \& Kyeyune, R. (2012). An analysis of E-learning information system adoption in Ugandan universities: Case of Makerere University business school. Information Technology Research Journal, 2 , 1), 1-1), 7 .

Misselbrook, A. (2008). Xerte user guide. The University of Northampton. Available at https://docplayer. net/48595458-Xerte-user-guide-v2-xerte-user-guide-created-by-anne-misselbrook.html. Visited on 2018 /05/12th. Visited on 2018/05/12th.

Mohapatra, S., \& Acharya, J. (2011). Public private partnership - participatory interventions to improve primary education in OPEPA. Journal of Case Research, 2, 2.

Mohapatra, S., \& Patra, D. (2017). User acceptance of web-based talent assessment platform (TAP). International Journal of Business Excellence, 12(4), 450-468.

Namukasa, K. I., Quinn, M., \& Janet Kaahwa, J. (2010). School mathematics education in Uganda: Its successes and its failures. Procedia Social and Behavioral Sciences, 2, 3104-3110. https://doi. org/10.1016/j.sbspro.2010.03.473.

POP, C. (2012). Evaluation of E-learning platforms: A case study. Informatica Economică vol. 16, no. 1/2012. Retrieved from http://www.revistaie.ase.ro/content/61/14\%20-\%20Pop.pdf. Visited on 2018/05/12th. Visited on 2018/05/12th.

Sarkar, S., Mohapatra, S., \& Pattanayak, S. (2018). Achieving success in the digital equalizer program through project management. Emerald Emerging Markets Case Studies, 8(2), 1-32. https://doi.org/10.1108 /EEMCS-05-2017-0102.

Slătineanug, L., Doduna, O., Panaiteb, E., Seghedinc, N., Nagîțd, G., Dusae, P., \& Neștianf, G. (2015). Analysis of an e-learning platform use by means of the axiomatic design. 9th international conference on axiomatic design - ICAD 2015. Procedia CIRP, 34, 244-249.

Trehan, S., \& Joshi, R. M. (2018). Building and evaluating logistic regression models for explaining the choice to adopt MOOCs in India. International Journal of Education and Development using Information and Communication Technology v14 n1 p33-51.

Willacy, H., \& Calder, N. (2017). Making mathematics learning more engaging for students in health schools through the use of apps. Education Sciences, 7, 48. https://doi.org/10.3390/educsci7020048.

Wright, F. J. (2010). Introduction to mathematical computing. Goldsmith's company mathematics course. Available at http://www.maths.qmul.ac.uk/ fjw/goldsmiths/2010/FJW/Introduction\%20to $\% 20$ Mathematical\%20Computing.pdf . Visited on 2018/05/12th

Publisher's note Springer Nature remains neutral with regard to jurisdictional claims in published maps and institutional affiliations. 